\title{
Starch behaviour in potato at temperatures close to cellular membrane breakdown**
}

\author{
Jiři Blahovec* and Pavel Kouřim \\ Department of Physics, Czech University of Life Sciences, 16521 Prague 6 - Suchdol, Czech Republic
}

Received January 8, 2018; accepted May 25, 2018

\begin{abstract}
A combined thermal analysis (including a dynamic mechanical analysis and a dielectric thermal analysis) was applied to the cortex tissues of long-stored potatoes in the temperature range of $30-90^{\circ} \mathrm{C}$, with the constant air relative humidity of $90 \%$. Two heating rates, i.e. $1^{\circ} \mathrm{C} \mathrm{min}^{-1}$ and $0.5^{\circ} \mathrm{C} \mathrm{min}^{-1}$, were used for temperature scanning. The obtained results were found to differ in the inspected temperature range, indicating either a different mode of drying or differences in the starch gelatinization mechanism, the latter being usually controlled by water availability in contact with starch in both tests. The observed results indicate new possibilities in the cooking strategies that are usually applied to potatoes.

Keywords: thermal analysis, starch, gelatinization, temperature, cell wall
\end{abstract}

\section{INTRODUCTION}

World-wide, potatoes are an important foodstuff. Their properties, including those that form their sensory profiles, sensitively depend on cultivar, the cultivation method and storage conditions (van Es and Hartmans, 1981). Potato tissue generally softens with increasing temperature, while also becoming more permeable either for different molecules or for electric charges (Personius and Sharp, 1938). This trend can be modified by some temperature dependent characteristic processes at temperatures above $50^{\circ} \mathrm{C}$, including starch gelatinization (Lelievre and Liu, 1994) and thermal modifications of the starch (Ratnayake and Jackson, 2007, 2009; Teste et al., 2004).

Gelatinization of potato starch has been studied by many researchers (Bao and Bergmann, 2004; Donald, 2004; Ratnayake and Jackson, 2009; Singh et al., 2003; Zoebel and Stephen, 2006), and starch changes during

*Corresponding author e-mail: blahovec@tf.czu.cz

**This work was supported by the Research Intention MSM 6046070905, Czech Republic (2007-2014). heating are easily detected by various techniques, including the differecial scanning calorimetry (DSC) thermal analysis (Lelievre and Liu, 1994). Such changes of the starch during heating are sensitively connected either with the structural properties of the starch grains or their dimensions and composition (Ratnayake and Jackson, 2007). The analysis of the gelatinization process shows the importance of starch composition, starch structure, water availability and the time scale factor of the process (Ratnayake and Jackson, 2009). The structural changes of the starch can be strongly modified by changing the timetemperature-moisture conditions (Gunaratne and Hover, 2002; Jiramuntakul et al., 2011; Tester and Debon, 2000), which also lead to fundamental changes in the animal and human starch digestibility (Lee et al., 2011, 2012; Lehman and Robin, 2007; Parada and Aquilera, 2009). Slowly digestible starch (SDS) offers the advantage of a slow increase in the postprandial blood glucose levels and sustained blood glucose levels over time, when compared to rapid digestible starch with its fast and high peak, as well as fast decline.

Our previous studies of starch effects in potato tubers were mainly based on the dynamic mechanical analysis (DMA) thermal analysis (Blahovec and Lahodová, 2011, 2013a,b). Therein, sharp peaks were observed at temperatures higher than those at which gelatinization had previously been detected by the DSC thermal analysis (e.g. Karlsson and Elliasson, 2003a,b). These peaks are denoted as 'starch peaks'. The same DMA method, when applied to carrot (Blahovec and Lahodová, 2012), a plant practically without any starch, indicated similar effects at temperatures

(C) 2018 Institute of Agrophysics, Polish Academy of Sciences 
where the 'starch peaks' in potato had previously been observed. These effects were later identified (Blahovec and Kouřim, 2016) as the destruction of the cellular membrane. This was also microscopically detected in potato (Imaizumi et al., 2015) close to the above-mentioned temperatures. The DMA results were also supported by direct electric measurements (the DETA thermal analysis), as presented in our previous paper (Blahovec and Kouřím, 2016).

The previous results showed certain similarities between the effects observed via two different thermal methods in potato and carrot, even though the two fleshes differ in terms of the presence of a very important component: the cellular starch. This is why we returned after five years to a thermal analysis of potato tubers, with the aim of clarifying the similarities and differences in thermal behaviour of both potato and carrot. For this reason, we employed the repeatedly combined DMA and DETA thermal analysis method.

\section{MATERIALS AND METHODS}

Potato cultivar 'Janet' was cultivated in standard conditions by the Potato Research Institute (PRI) in Havlickuv Brod. The tubers were stored after harvest for approximately three months in cold and wet conditions $\left(6^{\circ} \mathrm{C}, 85 \%\right.$ relative humidity), and then transported to the laboratory. After a few days of storage in a refrigerator at $7 \pm 1^{\circ} \mathrm{C}$, they were washed in cold water. The selected defect-free tubers of medium size ( 5 to $8 \mathrm{~cm}$ in diameter) were then left at room temperature in order to be tested on the following day.

Rectangular specimens (width, thickness, length: 5.5, $4.0,30 \mathrm{~mm}$, respecitvely) with their long axis parallel to the tuber axis (between the stem and the bud) were cut from the central part of the cortex (i.e., the cortex on the border between stem and bud parts) of the tested tuber using special cutting jigs. One specimen of each type was prepared from each tuber.

The DMA experiment was performed using the DX04TC variant of a special DMA instrument, constructed by RMI (Pardubice, Czech Republic). The specimen was mechanically fixed in two points so that the longitudinal axis was perpendicular to the fixing jaws. The free length of the specimen between the jaws was $11 \mathrm{~mm}$. The height of the fixed specimen was approx. $4.0 \mathrm{~mm}$. One of the jaws was fixed, while the other moved up and down with a constant amplitude of $0.5 \mathrm{~mm}$ and a frequency of $0.2 \mathrm{~Hz}$. The force connected with the oscillation was recorded (about 3 records per minute), providing the basis for the complex module determination (storage - SM and loss - LM). The module values (originally in $\mathrm{Pa}$ ) sensitively depended on the precise form of the tested specimen. To prevent this source of variation, we calculated the resulting SM and LM values as a ratio of the value obtained for $\mathrm{SM}$ at $30^{\circ} \mathrm{C}$. This method proved suitable for both determining the peak positions and conducting the slope analysis.
The DMA instrument was modified so that the electric properties of the tested specimen could be measured either as a real conductor, via its complex impedance, or a real capacitor (described through its complex permittivity). For details, see Blahovec and Kouř́m (2016). The impedance components were measured and recorded continuously by the RLC Hameg 8118 meter (a voltage of approx. $1 \mathrm{~V}$, a frequency of $20 \mathrm{kHz}$ and the same sampling as DMA). The electric measurements represented a form of DETA (the dielectric thermal analysis).

Every experiment started at a temperature of $30^{\circ} \mathrm{C}$ and air humidity in the test chamber of $90 \%$. The humidity was kept constant during the whole experiment. The temperature scan proceeded up to $90^{\circ} \mathrm{C}$, with two alternative rates of 0.5 and $1 \mathrm{~K} \mathrm{~min}^{-1}$. Every test was repeated ten times. The obtained data were unified into one package that was ordered by the increasing temperature. The mean value and standard deviations, as basic statistical functions, were calculated for all data falling into $1 \mathrm{~K}$ steps in the temperature scale.

The experimental results were analysed using the standard laboratory software Origin ${ }^{\circledR}$, OriginPro Ver. 7 (Origin Lab, Northampton, MA, USA). The analysis focused on the phase analysis of the obtained DMA and DETA values. Temperature derivatives of the experimental functions were calculated and the slope analysis was applied to the temperature plot of the impedance phase shifts. Data smoothing was initially performed by averaging the 5 neighbour points in the set, followed by the smoothed data differentiation. The basic statistical analysis of the individual classes was then performed using a special FORTRAN program made for this purpose.

We evaluated two basic parameters, i.e. the real and imaginary components of the specimen impedance during the heating test. Whereas the real component is always a positive number, the imaginary component of the plant flesh is always negative due to its capacitive character. The data were usually recalculated, i.e. both impedance components were divided by the initial value (approx. at $30^{\circ} \mathrm{C}$ ) of the real component. The imaginary component is represented in this paper by its negative value, while the term "tangent" stands for the minus tangent of the phase shift between the imaginary and real components of the impedance, being calculated as a ratio between the imaginary and real components.

\section{RESULTS AND DISCUSSION}

Examples of the impedance presentation in the DETA test. Figure 1 provides, for the impedance plots, the characteristic temperature range $\mathrm{X}$ that can be defined as the temperature range in which the real impedance component does not change significantly whereas the imaginary component decreases, creating conditions for the tangent to decrease. The whole temperature range can be then divided 

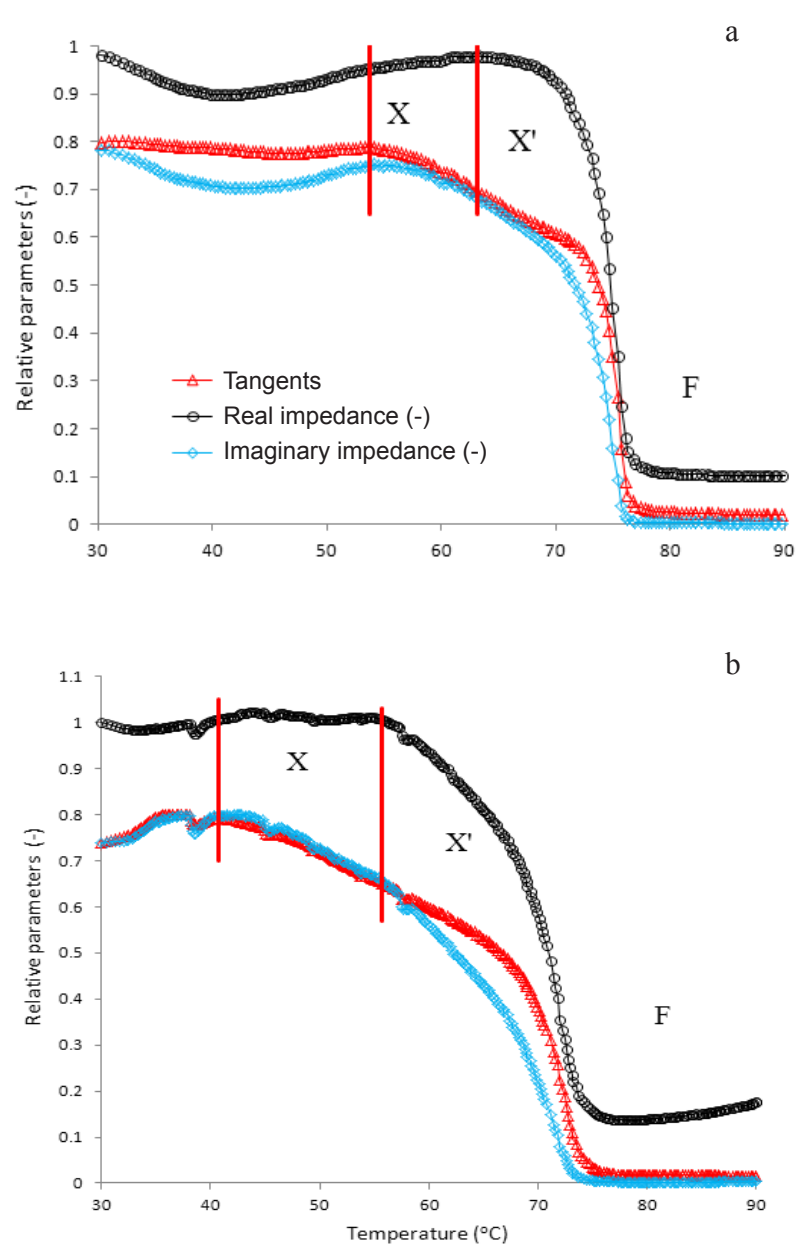

Fig. 1. Typical temperature plots of DETA parameters between 30 and $90^{\circ} \mathrm{C}$. For details see Material and Methods. The lines approximately denote temperature range $\mathrm{X}$. Herein, both the imaginary component and the calculated tangent decrease, while the real component does not drop. $X^{\prime}$ denotes the initial area of the rapid impedance decrease, $\mathrm{F}$ denotes the final part of the process, heating rate: $\mathrm{a}-1 \mathrm{~K} \mathrm{~min}^{-1}, \mathrm{~b}-0.5 \mathrm{~K} \mathrm{~min}^{-1}$.

into the first part with temperatures lower than in X (denoted as $\mathrm{XL}$ ), range $\mathrm{X}$, the part with temperatures higher than in $X\left(\right.$ denoted as $X^{\prime}$ ) and the final part $F$ which is separated from $X^{\prime}$ by a very narrow temperature range in which all plotted quantities sharply fall down. The definition of borders $\mathrm{X}$ is given in the caption to Fig. 1.

In the DETA analysis, we mainly used the tangent parameters. The tangent plots versus temperature (Fig. 1) were analysed using a numerical derivative, with the aim of obtaining more information on the details of the tangenttemperature plots. In range $X^{\prime}$ (Fig. 1), the plots show several sharp peaks (Fig. 2). These peaks are represented by the most abrupt decreases in the modified tangent curves in Fig. 1a,b, and they separate range X' from the final parts (F) of the plots in which tangents are relatively stable, with a possible small increase (pay attention to the plot sign that is defined in the figure caption).

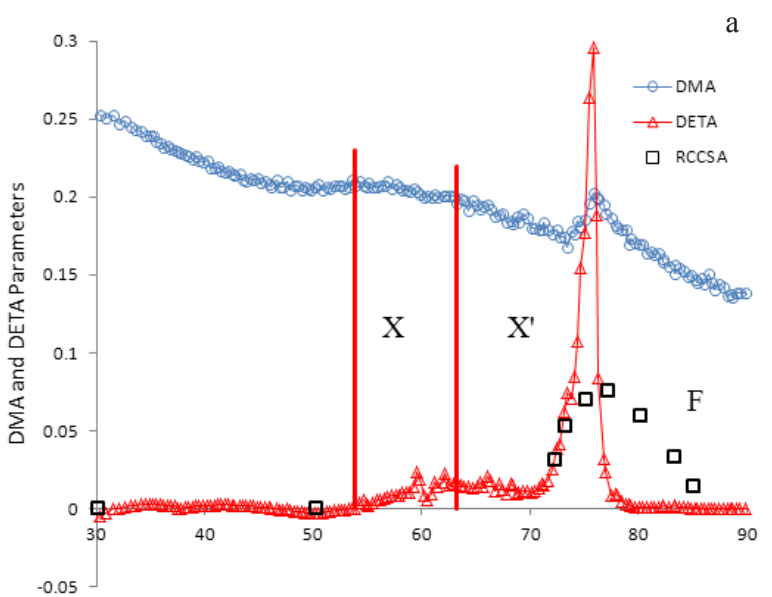

a

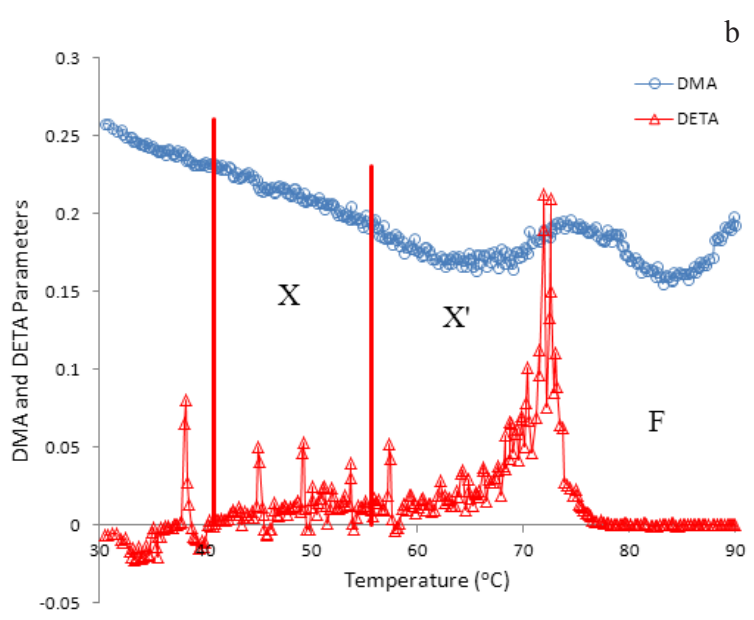

Fig. 2. Examples of temperature plots of the main phase characteristics obtained in DMA and DETA tests. In the upper parts of the figures, the loss tangent observed in DMA tests is given. In the lower parts of the figures, there are plots of temperature derivatives of tangent from DETA tests are given (see Figs 1a, b, also for symbols $\mathrm{X}, \mathrm{X}^{\prime}$, and $\mathrm{F}$ ): a - heating rate $1 \mathrm{~K} \mathrm{~min}^{-1}$, in this part the relative cell cross section area (RCCSA) for potato cell heated in oil (heating rate $40 \mathrm{~K} \mathrm{~min}^{-1}$ ) is also given (Aguilera et al., 2001); $\mathrm{b}$ - heating rate $0.5 \mathrm{~K} \mathrm{~min}^{-1}$.

A combination of the two processes forms the initial parts of the plots in Fig. 1, i.e. the increasing conductivity of the cellular juice with increasing temperature (i.e. decrease of the real impedance with increasing temperature), and the increasing value of the real impedance due to specimen drying. Changes in the specimen dimensions during heating could also play some role. Range X is characterized by the initiation of water transport from the intracellular to intercellular spaces where water is continually evaporated, but the drying of cells also changes the ion membrane equilibrium, leading to the observed decrease in the imaginary impedance (Blahovec and Kouřím, 2017). This process can be understood as being a thermally activated damage of the cellular pore function, probably due to protein denaturation 
(e.g. myosin, Vilgis, 2015). Range $\mathrm{X}^{\prime}$ is a continuation of the processes responsible for creating range $\mathrm{X}$, with a larger electric current flowing through the cells.

Range $X^{\prime}$ ends in a quick loss of the specimen impedance (Personius and Sharp, 1938), which is well described by the impedance temperature slopes (Fig. 2). The quick loss of the specimen impedance is related to the noticeable destruction of the cellular membranes (Imaizumi et al., 2015; Sjoo et al., 2009). The impedance development in ranges $\mathrm{X}$ and $\mathrm{X}$ ' can be understood as a consequence of the cellular membrane conductivity changes. At the same time, the properties of the conducting electrolyte change, either due to water gain from the vacuoles on one side, and/or water evaporation on the other side. Moreover, the electrolyte conductivity changes along with increasing temperature. Originally, the vacuoles contain about $84 \%$ of all water located within the potato cells (Aguilera et al., 2001).

Numerical evaluation of the experimental data is given in Tables 1 and 2. Table 1 shows that the temperature range of $\mathrm{X}$ for the heating rate of $0.5 \mathrm{~K} \mathrm{~min}^{-1}$ is shifted by about $5-10 \mathrm{~K}$ to the lower temperatures, compared to the heating rate of $1 \mathrm{~K} \mathrm{~min}^{-1}$. At the same time, the tangent in range $\mathrm{X}$ has common limits for both heating rates (Fig. 3, they are 0.795 and 0.668 for the upper and lower tangent borders, respectively). Mean values of the relative lower X borders (a ratio of the lower and upper tangent borders) are given in Table 1 (End X RV), and they are approximately at the same levels of 0.883 and 0.884 for 1 and

Table 1. Characteristic data for tangent parameter in the DETA thermal analysis

\begin{tabular}{|c|c|c|c|c|c|c|c|c|}
\hline \multirow{3}{*}{$\begin{array}{c}\text { Temperature } \\
\text { rate } \\
\left(\mathrm{K} \mathrm{min}^{-1}\right)\end{array}$} & \multicolumn{4}{|c|}{ Decrease in $\mathrm{X}$} & \multirow{2}{*}{\multicolumn{2}{|c|}{$\begin{array}{c}\text { End X RV* } \\
(-)\end{array}$}} & \multirow{2}{*}{\multicolumn{2}{|c|}{$\begin{array}{c}\text { Peak }{ }^{* *} \\
\text { Position }\left({ }^{\circ} \mathrm{C}\right)\end{array}$}} \\
\hline & \multicolumn{2}{|c|}{ Beginning $\left({ }^{\circ} \mathrm{C}\right)$} & \multicolumn{2}{|c|}{ End $\left({ }^{\circ} \mathrm{C}\right)$} & & & & \\
\hline & MV & $\mathrm{SD}$ & MV & $\mathrm{SD}$ & MV & SD & $\mathrm{MV}$ & SD \\
\hline 1 & 52.0 & 1.3 & 61.7 & 1.9 & 0.883 & 0.056 & 75.4 & 1.1 \\
\hline 0.5 & 41.5 & 1.0 & 56.4 & 1.5 & 0.884 & 0.028 & 73.1 & 0.8 \\
\hline
\end{tabular}

$\mathrm{MV}$ - mean value, $\mathrm{SD}$ - standard deviation, $\mathrm{RV}$ - relative value. *Mean values of the relative lower X borders (a ratio of the lower and upper tangent borders). **The peak position of temperature derivatives for the tangent parameter (see Fig. 2).

Table 2. Relative final values (-) of the real $\left(R_{f}\right)$ and imaginary $\left(I_{f}\right)$ components

\begin{tabular}{ccccccccc}
\hline \multirow{2}{*}{$\begin{array}{c}\text { Temperature rate } \\
\left(\mathrm{K} \mathrm{min}^{-1}\right)\end{array}$} & \multicolumn{2}{c}{$\mathrm{R}_{\mathrm{f}}$} & \multicolumn{2}{c}{$\mathrm{R}_{\min }$} & \multicolumn{2}{c}{$\mathrm{T}_{\min }$} & \multicolumn{2}{c}{$\mathrm{I}_{\mathrm{f}}$} \\
\cline { 2 - 9 } & $\mathrm{MV}$ & $\mathrm{SD}$ & $\mathrm{MV}$ & $\mathrm{SD}$ & $\mathrm{MV}$ & $\mathrm{SD}$ & $\mathrm{MV}$ & $\mathrm{SD}$ \\
\hline 1 & 0.107 & 0.009 & 0.107 & 0.009 & 89.7 & 0.6 & 0.00255 & 0.00035 \\
0.5 & 0.183 & 0.024 & 0.0946 & 0.0120 & 79.6 & 1.0 & 0.00377 & 0.00085 \\
\hline
\end{tabular}

Relative components of impedance in the final parts of the plots - see the part denoted F in Figs 1-3. $R_{\min }$ and $T_{\min }$ identify the minimum value on R-T plot, where applicable. Explanation as in Table 1.

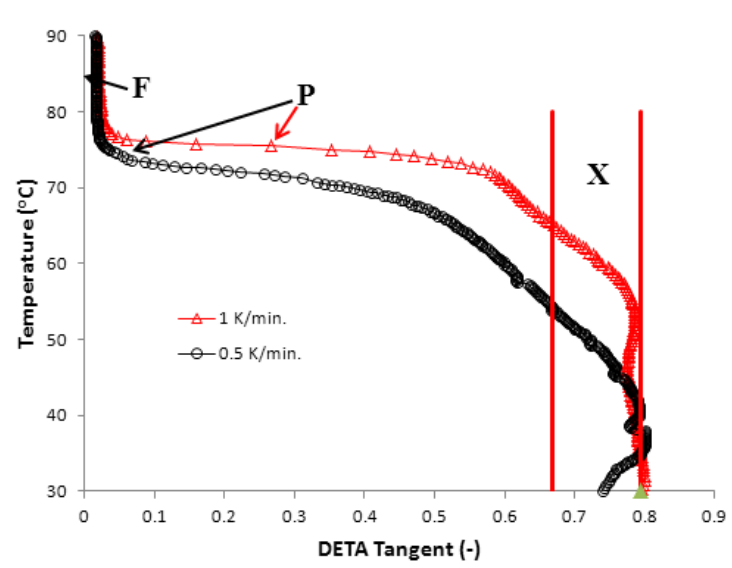

Fig. 3. Plot of temperature versus DETA tangent in two tests of different temperature rate. The important stages of the process are denoted (X, P, and F). The symbol $\mathrm{P}$ denotes the position of the maximum tangent change. For other symbols see Fig. 1. The stage $\mathrm{X}$ is given by nearly the same boundaries in DETA Tangent (from the left side the boundaries are 0.696 and 0.668 for temperatures rates 1 and $0.5 \mathrm{~K} \mathrm{~min}^{-1}$, respectively).
$0.5 \mathrm{~K} \mathrm{~min}^{-1}$, respectively. The peaks in the temperature tangent derivatives of both tested cases are similar, but of different 'thickness' and position (in the case of $0.5 \mathrm{~K} \mathrm{~min}^{-1}$, the peak is at about $2 \mathrm{~K}$ lower than the peak in the case of $1 \mathrm{~K} \mathrm{~min}^{-1}$ ) (Fig. 2). Furthermore, the peaks were observed at lower tangent values in the case of $0.5 \mathrm{~K} \mathrm{~min}^{-1}$ compared to $1 \mathrm{~K} \mathrm{~min}^{-1}$ (Fig. 3).

Significant differences were observed in the final parts of the heating curves obtained at different heating rates. Whereas at the rate of $1 \mathrm{~K} \mathrm{~min}^{-1}$ the tangent in this part was relatively stable and slowly decreased with an increase in temperature in the observed range up to $90^{\circ} \mathrm{C}$, at the rate of $0.5 \mathrm{~K} \mathrm{~min}^{-1}$, in the same temperature range, both impedance components increased with increasing temperature. In this case we observed a minimum value $R_{\min }$, of approximately 0.0946 at a temperature of $79.6^{\circ} \mathrm{C}$, and a nearly doubled final value of 0.183 at $90^{\circ} \mathrm{C}$. The systematically higher impedance values at the heating rate of $0.5 \mathrm{~K} \mathrm{~min}^{-1}$, compared to the heating rate of $1 \mathrm{~K} \mathrm{~min}^{-1}$ (see also $\mathrm{I}_{\mathrm{f}}$ in Table 2), could be due to the higher level of drying in the slower test. 
Table 3. Characteristic data for loss tangent parameter in the DMA thermal analysis

\begin{tabular}{|c|c|c|c|c|c|c|c|c|}
\hline \multirow{3}{*}{$\begin{array}{l}\text { Temperature rate } \\
\qquad\left(\mathrm{K} \mathrm{min}^{-1}\right)\end{array}$} & \multicolumn{4}{|c|}{ Quasi-linear decrease } & \multicolumn{4}{|c|}{ Peak } \\
\hline & \multicolumn{2}{|c|}{ Beginning $\left({ }^{\circ} \mathrm{C}\right)$} & \multicolumn{2}{|c|}{ Finish $\left({ }^{\circ} \mathrm{C}\right)$} & \multicolumn{2}{|c|}{ Position $\left({ }^{\circ} \mathrm{C}\right)$} & \multicolumn{2}{|c|}{ Value $(\%)$} \\
\hline & MV & $\mathrm{SD}$ & MV & SD & MV & $\mathrm{SD}$ & MV & SD \\
\hline 1 & 58.6 & 6.6 & 70.4 & 2.0 & 75.4 & 0.6 & 0.19 & 0.01 \\
\hline 0.5 & 41.2 & 5.7 & 57.8 & 4.3 & 75.4 & 2.2 & 0.18 & 0.01 \\
\hline
\end{tabular}

Explanations as in Table 1.

The main results of the DMA test can be well demonstrated using DMA tangent plots (Fig. 2), in combination with the phase results of the DETA test. The obtained DMA results are similar to those obtained in our previous thermal studies of potatoes (Blahovec and Lahodová, 2011, 2013a,b). Herein, most parts of the DMA tangent versus temperature plots are represented by quasi-linear decreases (range $\mathrm{X}$ in Table 3 ). Parameters of the peaks with approximately the same locations as the peaks observed at the temperature derivatives of the parallel DETA tangents are also given in Table 3. Contrary to the DETA test, in the case of DMA, the peaks were observed at the same temperature $\left(75.4^{\circ} \mathrm{C}\right)$ for both heating rates $\left(1\right.$ and $\left.0.5 \mathrm{~K} \mathrm{~min}^{-1}\right)$. The peaks also have different widths and shapes. Furthermore, Fig. 2 shows that both peaks (in DMA at the loss tangent and in DETA at the tangent temperature derivative) are located at nearly the same temperatures. This indicates that the cell membranes collapse (Imaizumi et al., 2015) at approximately the same temperature as starch gelatinization and swelling in the individual cells (see information about cell dimension changes with increasing temperature, obtained in individual potato cells by Aguilera et al., 2001, which are replotted in Fig. 2a). Starch gelatinization is generally controlled by temperature and the presence of free water (Ratnayke and Jackson, 2009). The available methods for starch gelatinization detection may deliver slightly different results (Muñoz et al., 2015) so that the small differences observed in our experiments should not be overestimated. Moreover, it seems that the differences observed during the heating of potatoes to the same temperature, but with two different heating rates, are due to the different levels of drying brought about during heating with different heating rates. The role of drying can be also observed in the final part of the test, at the heating rate of $0.5 \mathrm{~K} \mathrm{~min}^{-1}$, where an increase in the DMA tangent was observed with increasing temperature, while the same trend was not observed at the heating rate of $1 \mathrm{~K} \mathrm{~min}^{-1}$.

Our experiments revealed that, with a slow heating of potatoes at temperatures above $40^{\circ} \mathrm{C}$ and below approx. $70^{\circ} \mathrm{C}$, the potato impedance (and mainly its imaginary component) started to decrease. Imaizumi et al. (2015) obtained similar results above $60^{\circ} \mathrm{C}$, and the observed changes were attributed to the decrease in intercellular resistance. We assume that this process is caused by the changes in potato cellular membranes, including especially in the function of the cellular pores that allow not only water but also ions to move from the cells to the intercellular space, and through the intercellular pores to outside the potato tissue. Hence, the tissue starts to dry (Blahovec and Kouř́m, 2017).

The individual cells lose water so that the mechanism of starch gelatinization could be modified to match the processes that take place at higher temperatures (Ratnayake and Jackson, 2009). Gelatinization actually occurs at the temperature at which the cellular membranes (including those of the vacuoles) collapse and the cellular starch grains contact the free water surrounding them. Therefore, starch gelatinization appears at the temperature at which the cellular membranes collapse. The cellular walls are then filled by the expanding starch (Aguilera et al., 2001; Sjoo et al., 2009), and the cells start to be more rough, as it had been previously observed in potato by the DMA thermal analysis (Blahovec and Lahodová, 2011, 2013a,b). The starch DMA peaks are, therefore, formed by starch expansion inside the tissue cellular walls, and by the collapse contacts between the individual cellular walls, due to internal pressure produced by the expanding starch (Blahovec and Lahodová, 2013b; Sjoo et al., 2009).

We observed that the controlled heating of potato particles at temperatures between 40 and $70^{\circ} \mathrm{C}$ can be used to prepare products with starches of different thermal and structural history (Gunaratne and Hover, 2002; Ratnayake and Jackson, 2009). This is a way to produce cooked potatoes with different states of starch gelatinization (Jiramuntakul et al., 2011; Lehmann and Robin, 2007; Parada and Aquilera, 2009; Tester and Debon, 2000). Moisture content inside the heated potato particles with dimensions similar to the tested specimens is continuously reduced by a parallel drying process. We proved that the gelatinization process in potato could start only after reaching the temperature at which cellular membranes collapse (about $74^{\circ} \mathrm{C}$ ) and the water blocked by the membranes (in vacuoles and/or in intercellular space) is released for launching the gelatinization process. The role of the drying process can be modified by changing the heating protocol, and mainly by inducing high air humidity (by heating specimens directly in water or in a concentrated water vapour), or by quicker heating that prevents the effects of the evaporation in lower humidity conditions. Our results 
indicate that drying can help to establish the adequate conditions for the long-lasting low-temperature annealing of potato starch (McPherson and Jane, 1999; Nakazawa and Wang, 2003; Parada and Aquilera, 2009).

\section{CONCLUSIONS}

1. The starch peaks that were previously observed in potato tubers, using the dynamic mechanical analysis thermal analysis, result from cellular membrane destruction.

2. Membrane destruction in potatoes is observed at similar temperatures as in carrots.

2. The slow heating of potato pieces at temperatures well below the starch peak is followed by cell dewatering without any indication of starch gelatinization.

3. The thermal processing of potatoes in such conditions makes it possible to thermally modify starch into lower digestibility states, making it more suitable for direct human consumption.

3. Starch gelatinization in the heated potatoes appears together with the collapse of cellular membranes.

\section{ACKNOWLEDGEMENTS}

The authors wish to thank Dr. J. Vacek for the experimental material and Dr S. Yanniotis for valuable comments.

Conflict of interest: The Authors do not declare conflict of interest.

\section{REFERENCES}

Aguilera J.M., Cadoche L., Lope C., and Gutierrez G., 2001. Microstructural changes of potato cells and starch granules heated in oil. Food Res. Int., 34, 939-947.

Bao J. and Bergmann C.J., 2004. The functionality of rice starch. In: Starch in Food. Structure, Functions and Applications (Ed. A.-C. Elliasson). Woodhead Publishing Limited and CRC Oxford: Press LLC, 258-294.

Blahovec J. and Kouř́m P., 2016. Combined mechanical (DMA) and dielectric (DETA) thermal analysis of carrot at temperatures 30-90 ${ }^{\circ}$ C. J. Food Eng., 168, 245-250.

Blahovec J. and Kouř́m P., 2017. DMA and DETA thermal analysis of carrot during its drying at different air humidity. J. Food Eng., 195, 217-221.

Blahovec J. and Lahodová M., 2011. DMA peaks in potato cork tissue of different mealiness. J. Food Eng., 103, 273-278.

Blahovec J. and Lahodova M., 2012. Changes in carrot (Daucus carota) parenchyma at higher temperatures detected in vivo by dynamic mechanical (thermal) analysis. Biorheology, 49, 289-298.

Blahovec J. and Lahodová M., 2013a. DMA thermal analysis of different parts of potato tuber. Food Chemistry, 133, 1101-1106.

Blahovec J. and Lahodová M., 2013b. Storage induced changes of potato properties as detected by DMA. LWT - Food Science and Technology, 50, 444-450.
Donald A.M., 2004. Understanding starch structure and functionality. In: Starch in Food. Structure, Functions and Applications (Ed. A.-C. Elliasson). Woodhead Publishing Limited and CRC Oxford: Press LLC, 156-184.

Gunaratne A. and Hoover R., 2002. Effect of heat-moisture treatment on the structure and physicochemical properties of tuber and root starches. Carbohydrate Polymers, 49, 425-437.

Imaizumi T., Tanaka F., Hamanaka D., Sato Y., and Uchino T., 2015. Effects of hot water treatment on electrical properties, cell membrane structure and texture of potato tubers. J. Food Eng., 162, 56-62.

Jiramuntakul W., Puttanlek C., Rangsardtkong V., Punchaarnon S., and Uttapap D., 2011. Microstructural and physicochemical properties of heat-moisture treated waxy and normal starches. J. Food Eng., 104, 246-258.

Karlsson M.E. and Eliasson A-C., 2003a. Effects of time/temperature treatments on potato (Solanum tuberosum) starch: a comparison of isolated starch and starch in situ. J. Sci. Food Agric., 83, 1587-1592.

Karlsson M.E. and Eliasson A-C., 2003b. Gelatinization and retrogradation of potato (Solanum tuberosum) starch in situ as assessed by differential scanning calorimetry (DSC). Lebensmittel-Wissenschaft und-Technologie, 36, 735-741.

Lee C.J., Kim Y., Choi H.J., and Moon T.W., 2012. Slowly digestible starch from heat-moisture treated waxy potato starch: Preparation, structural characteristics and glucose response in mice. Food Chemistry, 133, 1222-1229.

Lee C.J., Shin S.I., Kim Y., Choi H.J., and Moon T.W., 2011. Structural characteristics and glucose response in mice potato starch modified by hydrothermal treatments. Carbohydrate Polymers, 83, 1879-1886.

Lehmann U. and Robin F., 2007. Slowly digestible starch - its structure and health implications: A Review. Trends in Food Sci. Technol., 18, 346-365.

Lelievre J. and Liu H., 1994. A review of thermal analysis studies of starch gelatinization. Thermochimica Acta, 246(2), 309-315.

McPherson A.E. and Jane J., 1999. Comparison of waxy potato with other root and tuber starches. Carbohydrate Polymers, 40, 57-70.

Muñoz L.A., Pedreschi F., Leiva A., and Aguilera J.M., 2015. Loss of birefringence and swelling behavior in native starch granules: Microstructural and thermal properties. J. Food Eng., 152, 65-71.

Nakazawa Y. and Wang Y-J., 2003. Acid hydrolysis of native and annealed starches and branch-structure of their Naegeli dextrins. Carbohydrate Research, 338, 2871-2882.

Parada J. and Aquilera J.M., 2009. In vitro digestibility and glycemic response of potato starch is related to granule size and degree of gelatinization. J. Food Sci., 74, E34-E38.

Personius C. and Sharp P.F., 1938. Permeability of potato-tuber tissue as influenced by heat. Food Res., 3, 525-541.

Ratnayake W. and Jackson D.S., 2007. New insight into the gelatiniation process of native starches. Carbohydrate Polymers, 67, 511-529.

Ratnayake W. and Jackson D.S., 2009. Starch gelatinization. Advances in Food and Nutrition Research, 55, 221-268. 
Singh N., Singh J., Kaur L., Sodhi N.S., and Gill B.S., 2003. Morphological, thermal and rheological properties of starches from different botanic sources. Food Chem., 81, 219-231.

Sjoo M.E., Eliasson A-C., and Autio K., 2009. Comparison of different methods for the study of starch and other components within potato cells. Food, 3, 39-44.

Tester R.F. and Debon S.J.J., 2000. Annealing of starch - A review. Int. J. Biological Macromolecules, 27, 1-12.

Tester R.F., Karkalas J., and Qi X., 2004. Starch- composition, fine structure and architecture. J. Cereal Sci., 39, 151-165.
Van Es A. and Hartmans K.J., 1981. Structure and chemical composition of the potato. In: Storage of Potatoes. Postharves behaviour, store design, store practice, handling. (Eds A. Rastovski, A. van Es et al.). Centre for Agric. Publ. and Documentation, Wageningen, the Netherlands.

Vilgis T.A., 2015. Soft matter food physics - the physics of food and cooking. Reports Progress in Physics, 78, 124602.

Zoebel H.F. and Stephen A.M., 2006. Starch: Structure, analysis and application. In: Food Polysaccharides and Their Application (Eds A.M. Stephen, G.O. Phillips and P.A. Williams). CRC Press, Boca Raton, FL, USA. 